\title{
Solar PV-Powered SRM Drive for EVs with Flexible Energy Control Functions
}

\author{
Yihua Hu, Member, IEEE, Chun Gan, Student Member, IEEE, Wenping Cao, Senior Member, IEEE, \\ Youtong Fang, Stephen Finney
}

\begin{abstract}
Electric vehicles (EVs) provide a feasible solution to reducing greenhouse gas emissions and thus become a hot topic for research and development. Switched reluctance motors (SRMs) are one of promised motors for $\mathrm{EV}$ applications. In order to extend the EVs' driving miles, the use of photovoltaic (PV) panels on the vehicle helps decrease the reliance on vehicle batteries. Based on phase winding characteristics of SRMs, a tri-port converter is proposed in this paper to control the energy flow between the PV panel, battery and SRM. Six operating modes are presented, four of which are developed for driving and two for standstill on-board charging. In the driving modes, the energy decoupling control for maximum power point tracking (MPPT) of the PV panel and speed control of the SRM are realized. In the standstill charging modes, a grid-connected charging topology is developed without a need for external hardware. When the PV panel directly charges the battery, a multi-section charging control strategy is used to optimize energy utilization. Simulation results based on Matlab/Simulink and experiments prove the effectiveness of the proposed tri-port converter, which has potential economic implications to improve the market acceptance of EVs.
\end{abstract}

Index Terms-Electric vehicles, photovoltaics (PV), power flow control, switched reluctance motors (SRMs), tri-port converter.

\section{INTRODUCTION}

$\mathrm{E}$ lectric vehicles have taken a significant leap forward, by advances in motor drives, power converters, batteries and energy management systems [1]-[4]. However, due to the limitation of current battery technologies, the driving miles is relatively short that restricts the wide application of EVs [5]-[7]. In terms of motor drives, high-performance permanent-magnet (PM) machines are widely used while rare-earth materials are needed in large quantities, limiting the wide application of EVs [8][9].

In order to overcome these issues, a photovoltaic panel and a switched reluctance motor (SRM) are introduced to provide power supply and motor drive, respectively. Firstly, by adding the PV panel on top of the EV, a sustainable energy source is achieved. Nowadays, a typical passenger car has a surface enough to install a 250-W PV panel [Ref]. Second, a SRM needs no rare-earth PMs and is also robust so that it receives increasing attention in EV applications [10]-[16]. While PV panels have low power density for traction drives, they can be used to charge batteries most of time.

Generally, the PV-fed EV has a similar structure to the hybrid electrical vehicle, whose internal combustion engine (ICE) is replaced by the PV panel. The PV-fed EV system is illustrated in Fig. 1. Its key components include an off-board charging station, a PV, batteries and power converters [17]-[19]. In order to decrease the energy conversion processes, one approach is to redesign the motor to include some on-board charging functions [20]-[22]. For instance, paper [22] designs a 20-kW split-phase PM motor for EV charging, but it suffers from high harmonic contents in the back electromotive force (EMF). Another solution is based on a traditional SRM. Paper [23] achieves on-board charging and power factor correction in a $2.3-\mathrm{kW}$ SRM by employing machine windings as the input filter inductor. The concept of modular structure of driving topology is proposed in paper [24]. Based on intelligent power modules (IPM), a four-phase half bridge converter is employed to achieve driving and grid-charging. Although modularization supports mass production, the use of half/full bridge topology reduces the system reliability (e.g. shoot-through issues). Paper [25] develops a simple topology for plug-in hybrid electrical vehicle (HEV) that supports flexible energy flow. But for gridcharging, the grid should be connected to the generator rectifier that increases the energy conversion process and decreases the charging efficiency. Nonetheless, an effective topology and control strategy for PV-fed EVs is not yet developed. Because the PV has different characteristics to ICEs, the maximum power point tracking (MPPT) and solar energy utilization are the unique factors for the PV-fed EVs.

a::?::? PV

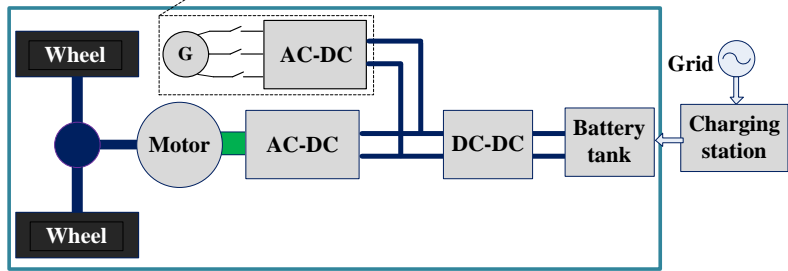

Fig. 1 PV-fed hybrid electrical vehicle.

In order to achieve low cost and flexible energy flow modes, a low cost tri-port converter is proposed in this paper to coordinate the PV panel, SRM and battery. Six operational modes are developed to support flexible control of energy flow.

\section{TOPOLOGY AND OPERATIONAL MODES}

\section{A. Proposed topology and working modes}

The proposed Tri-port topology has three energy terminals, PV, battery and SRM. They are linked by a power converter which consists of four switching devices $\left(S_{0} \sim S_{3}\right)$, four diodes $\left(D_{0} \sim D_{3}\right)$ and two relays, as shown in Fig. 2.

By controlling relays $\mathrm{J} 1$ and $\mathrm{J} 2$, the six operation modes are supported, as shown in Fig. 3; the corresponding relay actions are illustrated in Table I. In mode $1, \mathrm{PV}$ is the energy source to drive the SRM and to charge the battery. In mode 2, the PV and battery are both the energy sources to drive the SRM. In mode 3, the PV is the source and the battery is idle. In mode 4 , the battery is the driving source and the PV is idle. In mode 5, the battery is charged by a single-phase grid while both the PV and 
SRM are idle. In mode 6 , the battery is charged by the PV and the SRM is idle.

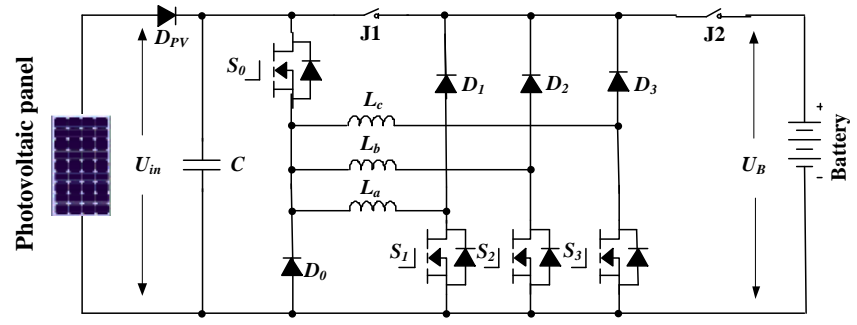

Fig. 2. The proposed Tri-port topology for PV-powered SRM drive.

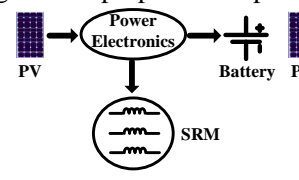

(a) Mode 1

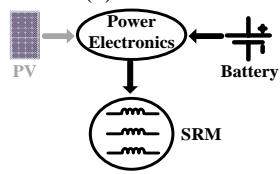

(d) Mode 4

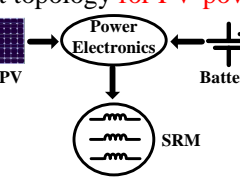

(b) Mode 2

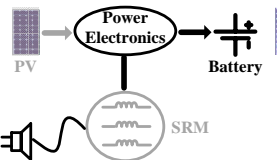

(e) Mode 5

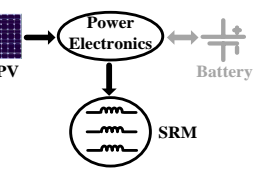

(c) Mode 3

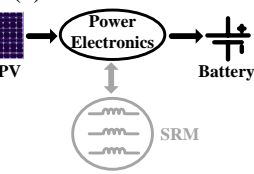

(f) Mode 6
Fig. 3. Six operation modes of the proposed Tri-port topology.

TABLE I J1 and J2 Actions under Different Modes

\begin{tabular}{|c|l|}
\hline Mode & \multicolumn{1}{|c|}{ J1 and J2 } \\
\hline 1 & J1 turn-off; J2 turn-on \\
\hline 2 & J1 and J2 turn-on \\
\hline 3 & J1 turn-on; J2 turn-off \\
\hline 4 & J1 and J2 turn-on \\
\hline 5 & J1 and J2 turn-on \\
\hline 6 & J1 turn-off; J2 turn-on \\
\hline
\end{tabular}

\section{B. Driving modes}

Operating modes 1 4 are the driving modes to provide traction drive to the vehicle.

(1) Mode 1

At light loads of operation, the energy generated from the PV is more than the SRM needed; the system operates in mode 1. The corresponding operation circuit is shown in Fig.4 (a), in which relay $\mathrm{J} 1$ turns off and relay $\mathrm{J} 2$ turns on. The PV panel energy feed the energy to SRM and charge the battery; so in this mode, the battery is charged in EV operation condition.

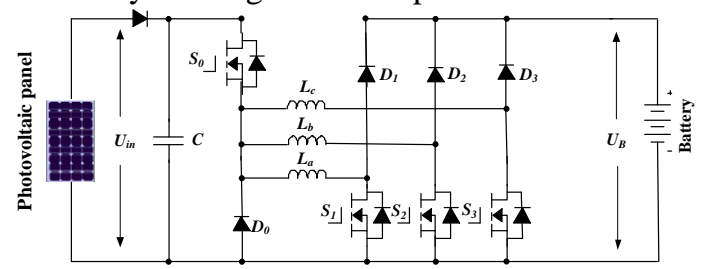

(a) Operation circuit under mode 1

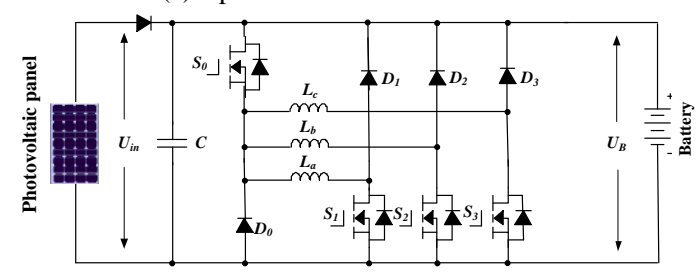

(b) Operation circuit under mode 2

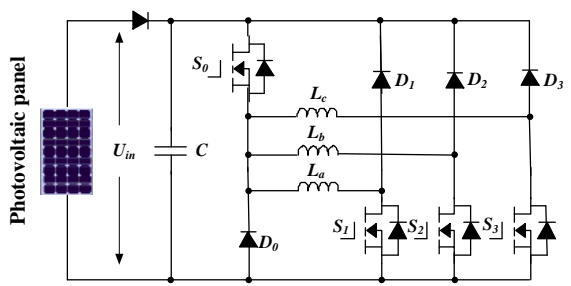

(c) Operation circuit under mode 3

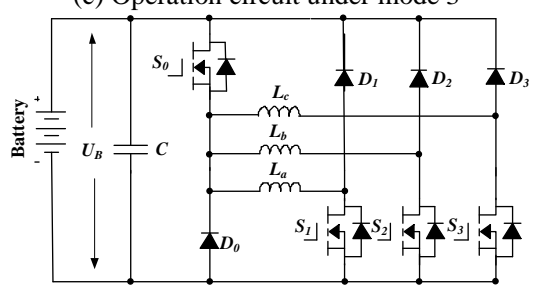

(d) Operation circuit under mode 4

Fig. 4 The equivalent circuits under driving modes.

(2) Mode 2

When the SRM operates in heavy load such as uphill driving or acceleration, both the PV panel and battery supply power to the SRM. The corresponding operation circuit is shown in Fig. $4(\mathrm{~b})$, in which relay $\mathrm{J} 1$ and $\mathrm{J} 2$ are turned on.

(3) Mode 3

When the battery is out of power, the PV panel is the only energy source to drive the vehicle. The corresponding circuit is shown in Fig. 4(c). J1 turns on and J2 turns off.

(4) Mode 4

When the PV cannot generate electricity due to low solar irradiation, the battery supplies power to the SRM. The corresponding topology is illustrated in Fig. 4(d). In this mode, relay $\mathbf{J} 1$ and $\mathbf{J} 2$ are both conducting.

\section{Battery charging modes}

Operating modes 5 and 6 are the battery charging modes.

(5) Mode 5

When PV cannot generate electricity, an external power source is needed to charge the battery, such as AC grid. The corresponding circuit is shown in Fig. 5(a). J1 and J2 turns on. Point $\mathrm{A}$ is central tapped of phase windings that can be easily achieved without changing the motor structure. Three phase windings are split and their midpoints are pulled out, as shown in Fig. 5(a). The central tapped node can be got without changing body structure of motor. Phase windings $L_{a 1}$ and $L_{a 2}$ are employed as input filter inductors. These inductors are part of the drive circuit to form an AC-DC rectifier for grid charging.

(6) Mode 6

When the EV is parked under the sun, the PV can charge the battery. J1 turns off; J2 turns on. The corresponding charging circuit is shown in Fig. 5(b).

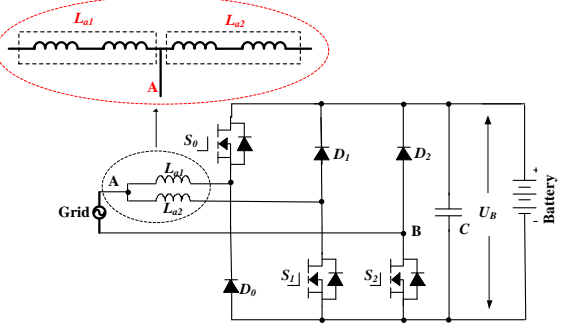

(a) Externat grid connected charging mode 


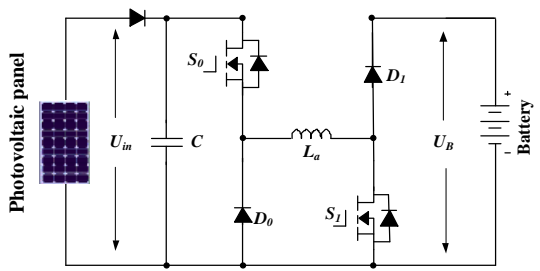

(b) PV source charging mode

Fig. 5 Equivalent circuits of charging condition modes.

\section{CONTROL STRATEGY UNDER DifFERENT MODES}

In order to make the best use of solar energy for driving the $\mathrm{EV}$, a control strategy under different modes is designed.

A. Single source driving mode

According to the difference in the power sources, there are PV-driving; battery-driving and PV and battery parallel fed source. In a heavy load condition, the PV power cannot support the EV, mode 2 can be adopted to support enough energy and make full use of solar energy. Fig. 6(a) shows the equivalent power source; the corresponding PV panel working points is illustrated in Fig. 6(b). Because the PV is paralleled with the battery, the PV panel voltage is clamped to the battery voltage $U_{B}$. In mode 2 , there are three working states: winding excitation, energy recycling and freewheeling states, as shown in Fig. 7. Modes 3 and 4 have similar working states to mode 2. The difference is that the PV is the only source in mode 3 while the battery is the only source in mode 4 .

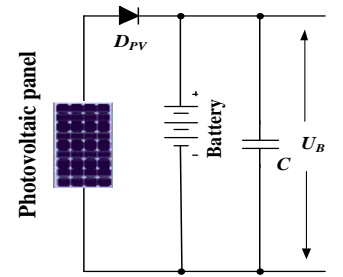

(a) Compound power source Fig. 6 Power supply at mode 2.

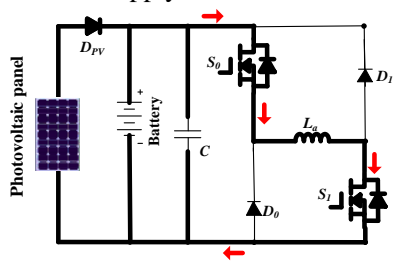

(a) Winding excitation state

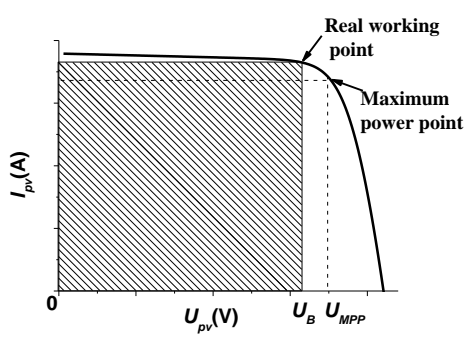

(b) Working point of the PV

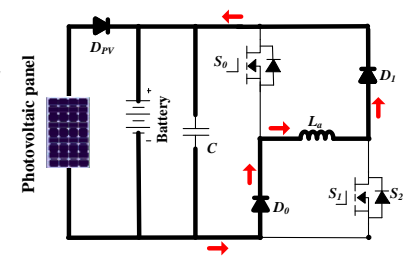

(b) Energy recycling state

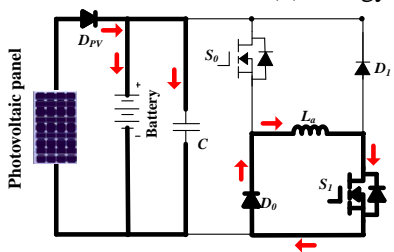

(c) Freewheeling state
Fig. 7 Working states at mode 2.

Neglecting the voltage drop across the power switches and diodes, the phase voltage is given by

$$
\begin{aligned}
U_{\text {in }} & =R_{k} i_{k}+\frac{d \psi\left(i_{k}, \theta_{r}\right)}{d t} \\
& =R_{k} i_{k}+L_{k} \frac{d i_{k}}{d t}+i_{k} \omega_{r} \frac{d L_{k}}{d \theta_{r}}, \quad k=a, b, c
\end{aligned}
$$

where $U_{\text {in }}$ is the DC-link voltage, $k$ is phase $a, b$, or $c, R_{k}$ is the phase resistance, $i_{k}$ is the phase current, $L_{k}$ is the phase inductance, $\theta_{r}$ is the rotor position, $\psi\left(i_{k}, \theta_{r}\right)$ is the phase flux linkage depending on the phase current and rotor position, and $\omega_{r}$ is the angular speed.

The third term in Eq. 1 is the back electromotive force (EMF) voltage given by

$$
e_{k}=i_{k} \omega_{r} \frac{d L_{k}}{d \theta_{r}}
$$

Hence, the phase voltage is found by

$$
U_{k}=R_{k} i_{k}+L_{k} \frac{d i_{k}}{d t}+e_{k}
$$

In the excitation region, turning on $S_{0}$ and $S_{I}$ will induce a current in phase $a$ winding, as show in Fig. 7(a). Phase $a$ winding is subjected to the positive DC bus voltage.

$$
+U_{\text {in }}=R_{k} i_{k}+L_{k} \frac{d i_{k}}{d t}+e_{k}
$$

When $S_{0}$ is off and $S_{1}$ is on, the phase current is in a freewheeling state in a zero voltage loop, as shown in Fig. 7(c), the phase voltage is zero.

$$
0=R_{k} i_{k}+L_{k} \frac{d i_{k}}{d t}+e_{k}
$$

In the demagnetization region, $S_{0}$ and $S_{1}$ are both turned off, and the phase current will flow back to the power supply, as show in Fig. 7(b). In this state, the phase winding is subjected to the negative DC bus voltage, and the phase voltage is

$$
-U_{\text {in }}=R_{k} i_{k}+L_{k} \frac{d i_{k}}{d t}+e_{k}
$$

In single source driving mode, the voltage-PWM control is employed as the basic scheme, as illustrated in Fig. 8. According to the given speed $\omega^{*}$, the voltage-PWM control is activated at speed control.

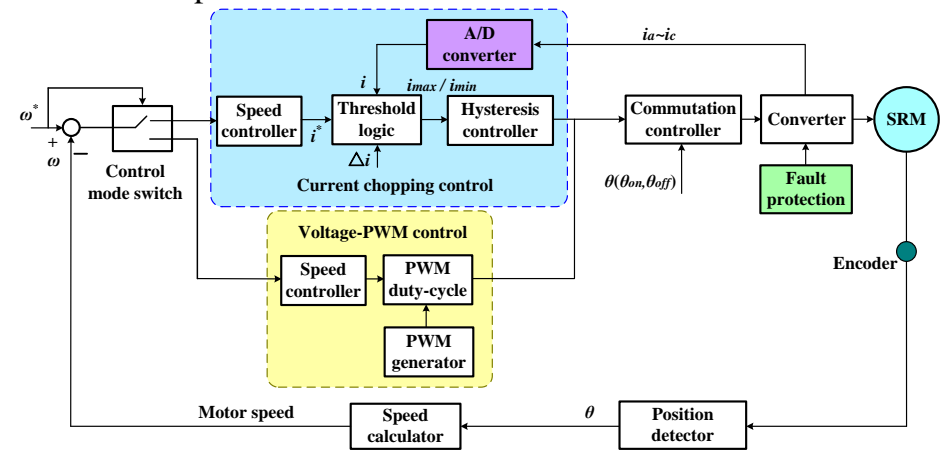

Fig. 8. SRM control strategy under single source driving mode.

\section{B. Driving-charging hybrid control strategy}

In the driving-charging hybrid control, the PV is the driving source and the battery is charged with the freewheeling current, as illustrated in drive mode 1. There are two control objectives: maximum power point tracking (MPPT) of the PV panel and speed control of the SRM.

The dual-source condition is switched from a PV-driving mode. Firstly, the motor speed is controlled at a given speed in mode 3 . Then, $\mathrm{J} 2$ is tuned on and $\mathrm{J} 1$ is off to switch to mode 1. By controlling the turn-off angle, the maximum power of PV panel can be tracked.

There are three steady working states for the dual-source mode (mode 1), as shown in Fig. 9. In Fig. 9(a), $S_{0}$ and $S_{I}$ conduct, the PV panel charges the SRM winding to drive the motor; In Fig. 9(b), $S_{0}$ and $S_{1}$ turn off; and the battery is charged with freewheeling current of the phase winding. Fig. 9(c) shows 
a freewheeling state.

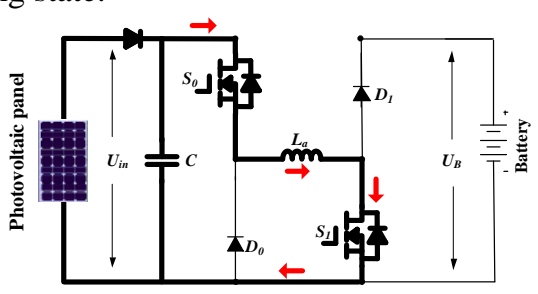

(a) Winding exciting state

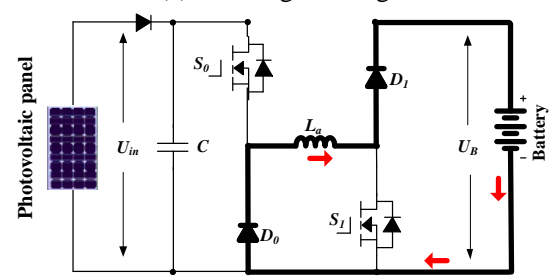

(b) Battery charging state

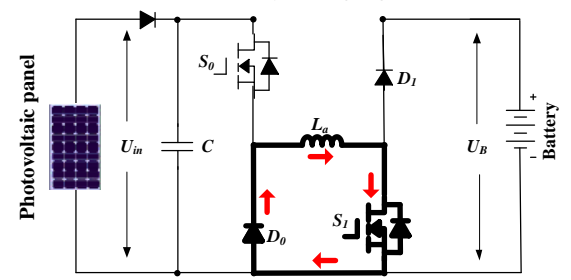

(c) Freewheeling state

Fig. 9 Mode 1 working states.

Fig.10 is the control strategy under driving-charging mode. In Fig. 10, $\theta_{\text {on }}$ is the turn on angle of SRM; $\theta_{\text {off }}$ is the turn-off angle of SRM. By adjusting turn-on angle, the speed of SRM can be controlled; the maximum power point tracking of PV panel can be achieved by adjusting turn-off angle, which can control the charging current to the battery.

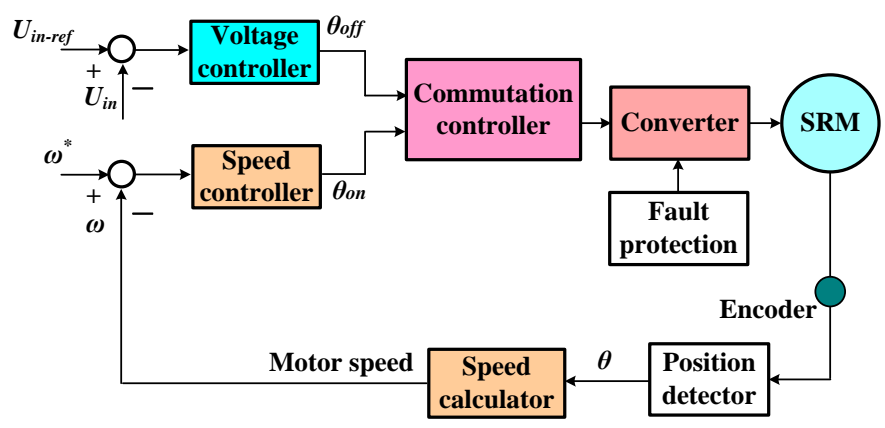

Fig. 10. Control strategy under driving-charging mode (mode 1)

\section{Grid-charging control strategy}

The proposed topology also supports the single-phase gridcharging. There are four basic charging states and $S_{0}$ is always turned off. When the grid instantaneous voltage is over zero, the two working states are presented in Fig. 11(a) and (b). In Fig. 11(a), $S_{1}$ and $S_{2}$ conduct, the grid voltage charges the phase winding $L_{a 2}$, the corresponding equation can be expressed as Eq. 7; In Fig. 11(b), $S_{1}$ turns off and $S_{2}$ conducts, the grid is connected in series with phase winding to charges the battery, the corresponding equation can be expressed as Eq. 8 .

$$
\begin{gathered}
U_{\text {grid }}=L_{a 2} \cdot \frac{d i_{\text {grid }}}{d t} \\
U_{B}-U_{\text {grid }}=L_{a 2} \cdot \frac{d i_{\text {grid }}}{d t}
\end{gathered}
$$

working states are presented in Fig. 11(c) and (d). In Fig. 8(c), $S_{1}$ and $S_{2}$ conduct, the grid voltage charges the phase winding $L_{a 1}$ and $L_{a 2}$, the corresponding equation can be expressed as Eq. (9); In Fig. 11(d), $S_{1}$ keeps conducing and $S_{2}$ turns off, the grid is connected in series with phase winding $L_{a 1}$ and $L_{a 2}$ to charges the battery, the corresponding equation can be expressed as Eq. 10 .
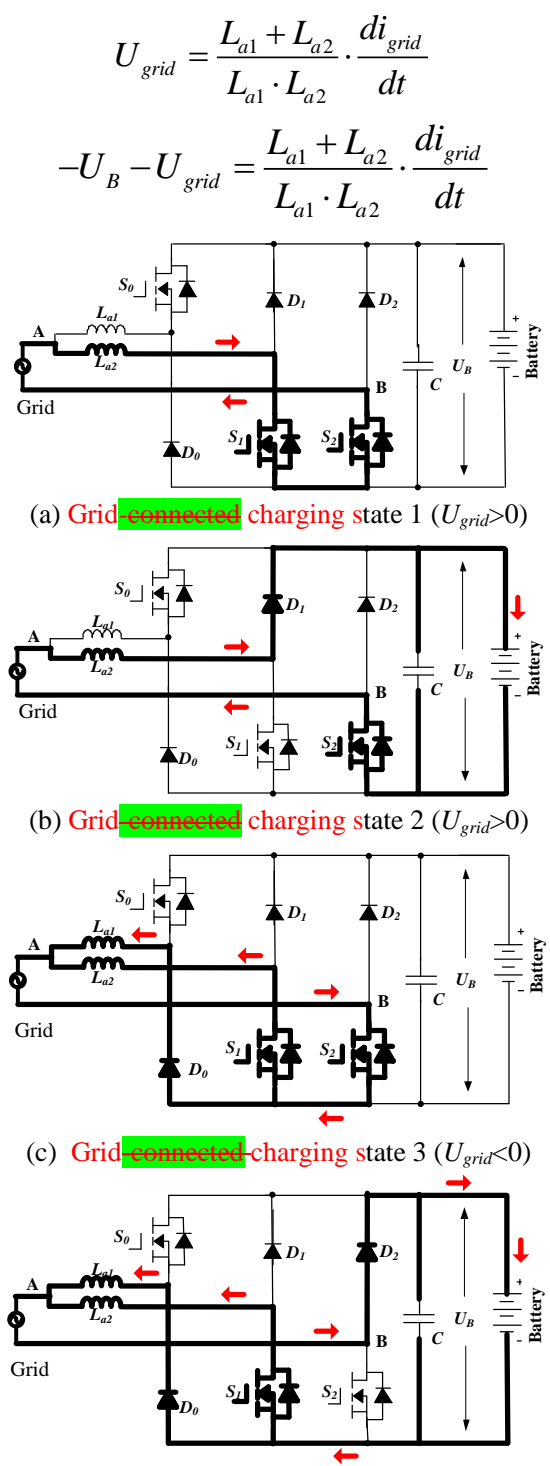

(d) Grid-connected charging state $4\left(U_{\text {grid }}<0\right)$

Fig. 11 Mode 5 charging states

In Fig. 12, $U_{\text {grid }}$ is the grid voltage; by the phase lock loop (PLL), the phase information can be got; $I_{\text {ref_grid }}$ is the given amplitude of the grid current. Combining $\sin \theta$ and $I_{\text {ref_grid, the }}$ instantaneous grid current reference $i_{\text {ref_grid }}$ can be calculated. In this mode, when $U_{\text {grid }}>0$, the inductance is $L_{a 2}$; when $U_{\text {grid }}<0$, the inductance is paralleled $L_{a 1}$ and $L_{a 2}$; in order to adopt the change in the inductance, hysteresis control is employed to realize grid current regulation. Furthermore, hysteresis control has excellent loop performance, global stability and small phase lag that makes grid connected control stable.

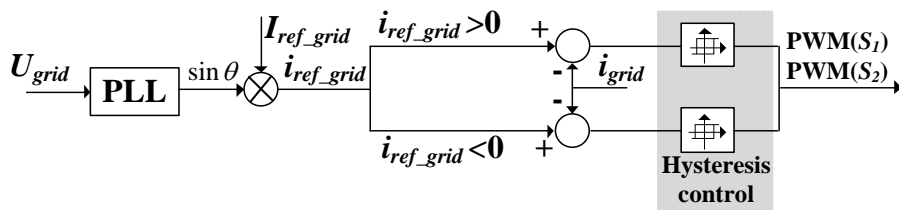

When the grid instantaneous voltage is below zero, the two 
Fig. 12 Grid-connected charging control (Mode 5).

D. PV-fed charging control strategy

In this mode, the PV panel charges the battery directly by the driving topology. The phase windings are employed as inductor; and the driving topology can be functioned as interleaved Buckboost charging topology. For one phase, there are two states, as shown in Fig. 13(a) and (b). When $S_{0}$ and $S_{1}$ turn on, the PV panel charges phase inductance; when $S_{0}$ and $S_{l}$ turns off, the phase inductance discharges energy to battery. According to the state-of-charging (SoC), there are three stages to make full use of solar energy and maintain battery healthy condition, as illustrated in Fig.13 (c). During stage 1, the corresponding battery $\mathrm{SoC}$ is in $0 \sim \mathrm{SoC} 1$, the battery is in extremely lack energy condition, the MPPT control strategy is employed to make full use of solar energy. During stage 2, the corresponding battery SoC is in SoC1 SoC2, the constant voltage control is adapted to charging the battery. During stage 3 , the corresponding battery $\mathrm{SoC}$ is in SoC2 1, the micro current charging is adapted. In order to simplify the control strategy, constant voltage is employed in PV panel MPPT control.

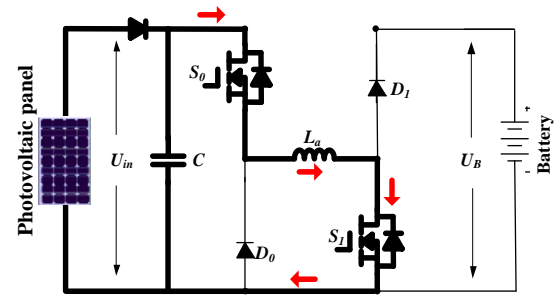

(a) Phase inductance charging state (mode 6)

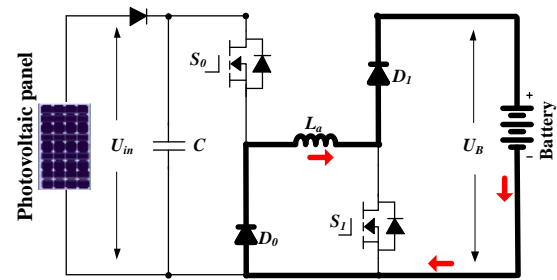

(b) Battery charging state (mode 6)

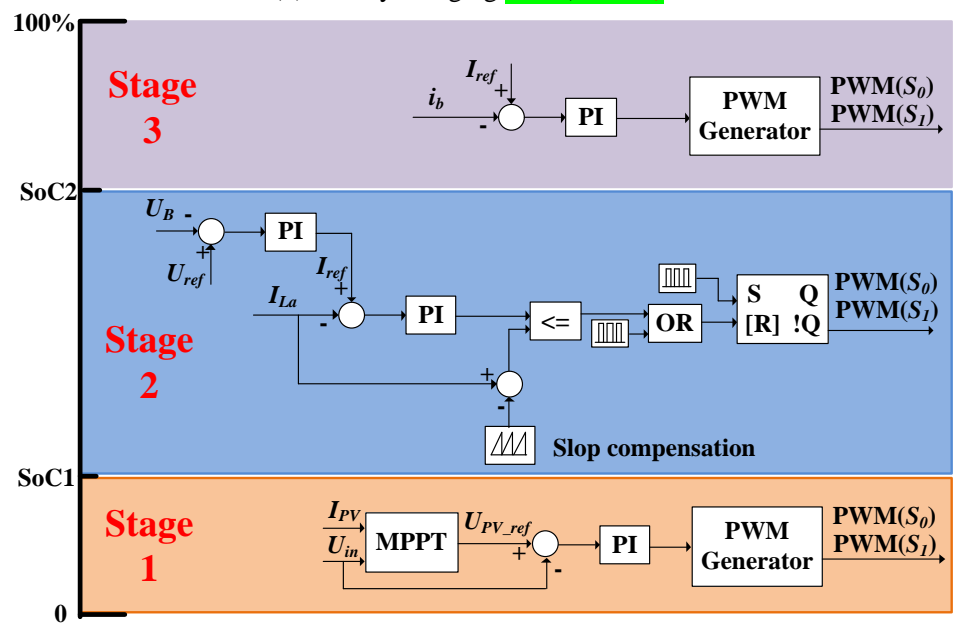

(c) Mode 6 charging control strategy.

Fig. 13 Mode 6 charging states and control strategy.

\section{SimUlation}

A $12 / 8$ SRM is first modeled in Matlab/Simulink using parameters in Table II. Fig. 14(a) presents the simulation results at mode 1. The load torque is set as $35 \mathrm{Nm}$, the PV panel voltage is controlled at the MPP. The freewheeling current is used to charge the battery. Fig. 14(b) shows the simulation results of the single-source driving modes (modes 2-4).
TABLE II Simulation parameters

\begin{tabular}{lc}
\hline \multicolumn{1}{c}{ Parameter } & Value \\
\hline SRM & $12 / 8$ \\
PV panel & $310 \mathrm{~V}$ \\
Maximum power point voltage reference voltage & $350 \mathrm{~V}$ \\
Battery voltage & $355 \mathrm{~V}$ \\
Constant voltage control reference voltage & $1 \mathrm{~A}$ \\
Constant current control reference current & $60 \mathrm{~A}$ \\
Mode 1, charging current & $1250 \mathrm{rmp}$ \\
Mode 4, driving speed & $355 \mathrm{~V}$ \\
Mode 6, constant voltage charging reference & $1 \mathrm{~A}$ \\
Mode 6, constant current charging reference & \\
\hline
\end{tabular}

Fig. 15 shows the simulation results of charging where Fig. 15(a) is for grid-charging. The positive half current quality is better than the negative half that is caused by the change in the grid-connected inductance.

Fig. 15(b) and (c) are for PV-charging. Fig. 15(b) presents the step change from stage 1 to 2 . In stage 1 , the battery is low in SoC. In order to achieve MPPT of the PV, the constantvoltage control is employed and the PV output voltage is controlled at MPP (310 V), as shown in Fig. 15(b). In stage 2, a constant voltage is adopted; the reference voltage is set to 355 V. As shown in Fig. 15(b), the charging converter output voltage is controlled at reference voltage in the step change from stage 1 to stage 2 . In stage 3, 1 A trickle charging is also achieved, as shown in Fig. 15(c).
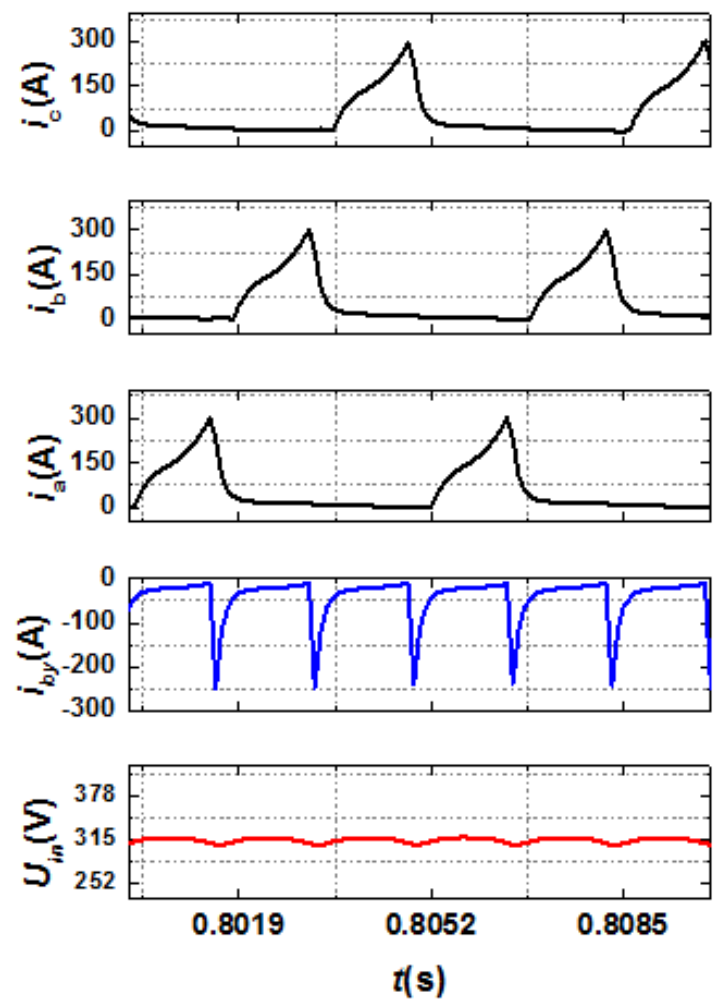

(a) Simulation results of driving-charging mode (mode 1) 

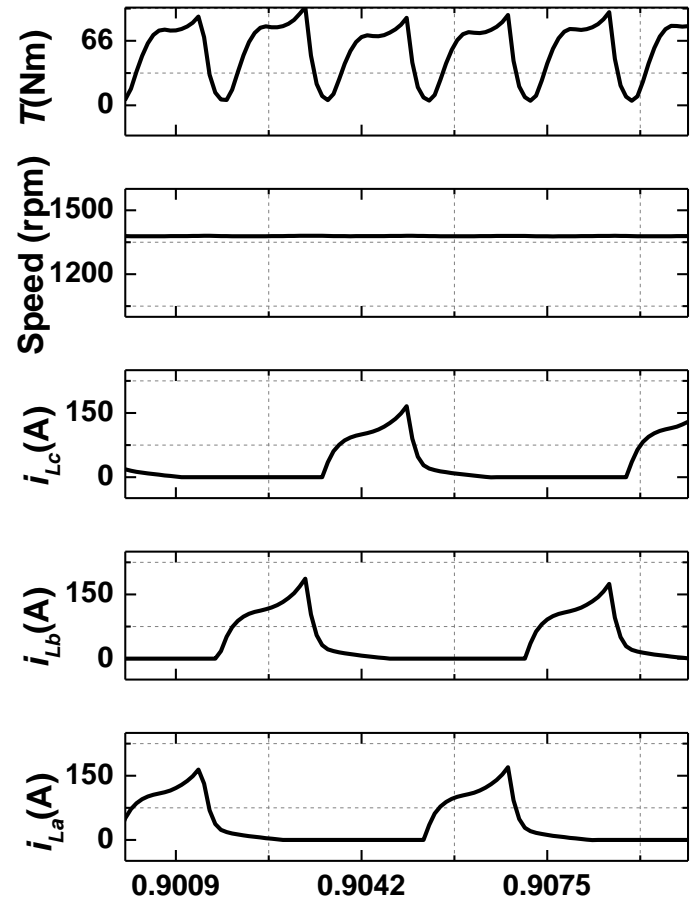

$t(s)$

(b) Simulation results of single source driving mode (modes 3 and 4)

Fig. 14 Simulation results for driving conditions at modes 1, 3 and 4 .
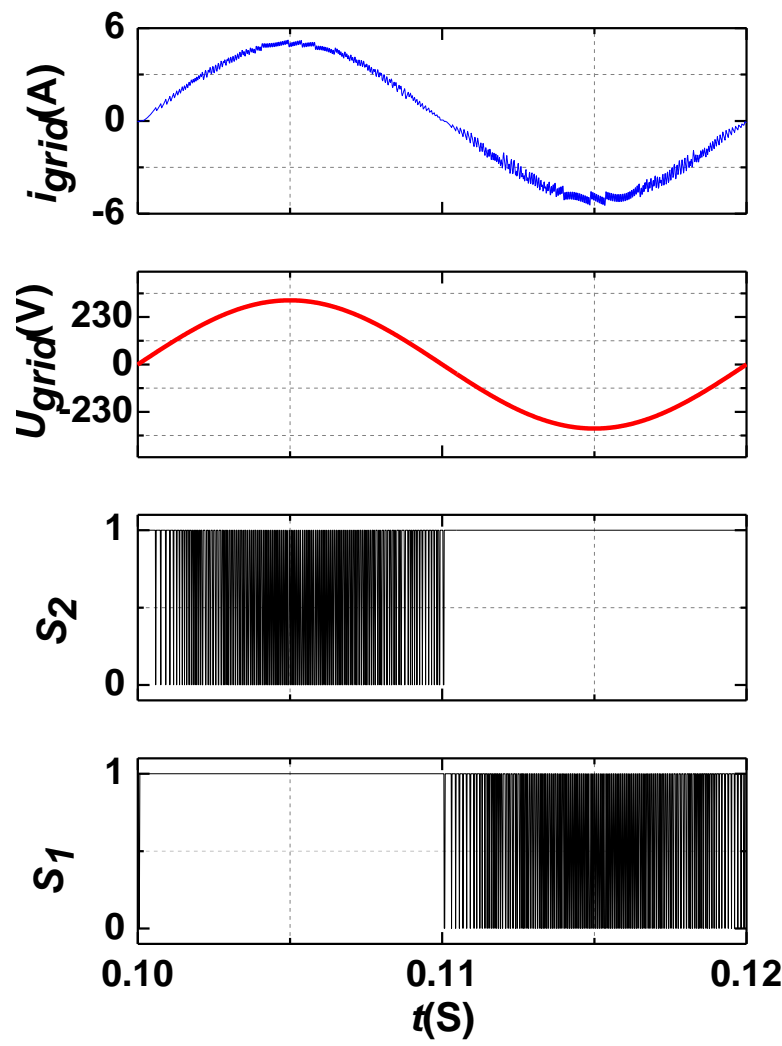

(a) Grid charging (mode 5)
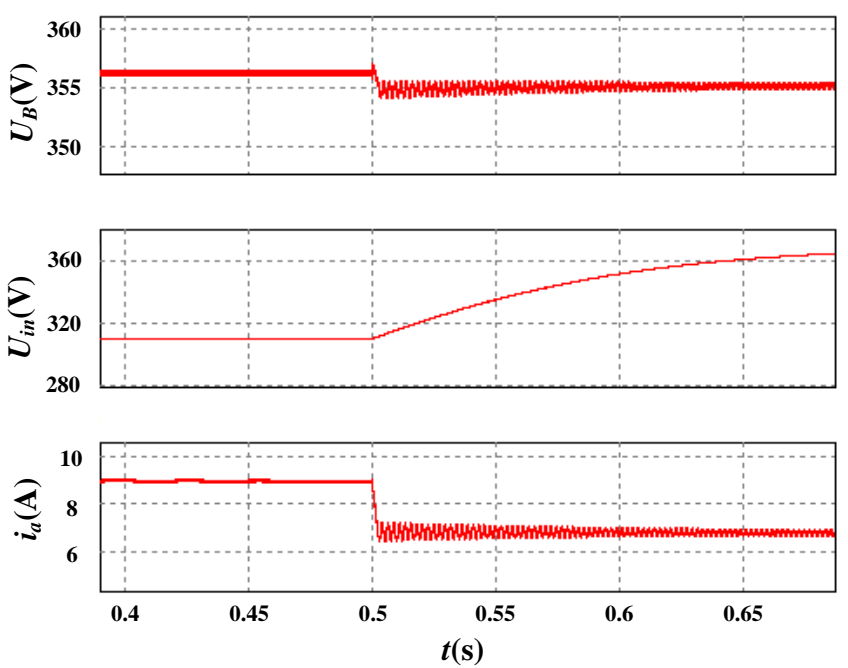

(b) PV charging mode 6 (stage 1 to stage 2)
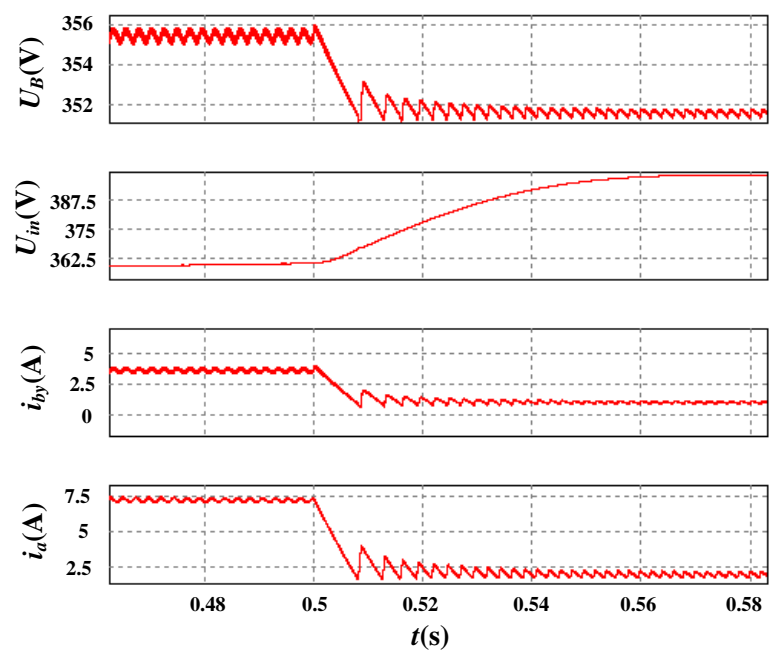

(c) PV charging (stage 2 to stage 3 )

Fig. 15 simulation results for charging modes.

\section{EXPERIMENTAL RESULTS}

The proposed scheme is validated by a $750-\mathrm{W}$ three-phase 12/8-pole prototype SRM, and the experimental setup is shown in Fig. 16. The motor parameters are presented in Table. III. A PV array simulator (Agilent Technology E4360A) is adopted as input source. A dSPACE-1006 board is employed as the main controller and PI is used for closed-loop control. A 24-V leadacid battery is used for charging and discharging tests. The rotor position and motor speed are calculated from an incremental encoder. An asymmetric-half bridge converter is used to dive the motor.

TABLE III Motor Parameters

\begin{tabular}{cc}
\hline Parameter & Value \\
\hline Phase number & 3 \\
Stator poles & 12 \\
Rotor poles & 8 \\
Rated speed $(\mathrm{r} / \mathrm{min})$ & 1500 \\
Rated power $(\mathrm{W})$ & 750 \\
Minimum phase inductance $(\mathrm{mH})$ & 27.2 \\
Maximum phase inductance $(\mathrm{mH})$ & 256.7 \\
Rotor outer diameter $(\mathrm{mm})$ & 55 \\
Rotor inner diameter $(\mathrm{mm})$ & 30 \\
Stator outer diameter $(\mathrm{mm})$ & 102.5 \\
Stator inner diameter $(\mathrm{mm})$ & 55.5 \\
Core length $(\mathrm{mm})$ & 80 \\
Stator arc angle $(\mathrm{deg})$ & 14 \\
\hline
\end{tabular}


The motoring and braking modes for the SRM when the relay $\mathrm{J} 1$ is on is shown in Fig. 17 , where $i_{a}, i_{b}$, and $i_{c}$ are the phase currents for phase A, B and C. The motor is powered by the battery in this condition. The turn-on and turn-off angles are set to $0^{\circ}$ and $20^{\circ}$, respectively, when motoring. In Fig. 17(c), the speed follows the given value well when it changes from 300 to $800 \mathrm{rpm}$, and stabilizes within $1.5 \mathrm{~s}$. The Inertial braking condition is presented in Fig. 17(d), however, the braking time is $2.5 \mathrm{~s}$, and the energy cannot flow to the power supply. In Fig. 17(e), the turn-on and turn-off angles are set to $22^{\circ}$ and $43^{\circ}$, respectively, when the motor runs in the regenerative braking mode, and the braking time is also decreased to $300 \mathrm{~ms}$.

Fig. 18 shows the motoring and braking modes for the drive when the relay $\mathrm{J} 1$ is off, where $i_{b y}$ is the current flowing out from the battery. Clearly, the battery is charged by the demagnetization current in motoring condition, as shown in Fig. 18(a) and (b). The energy is recycled to the battery when employing the regenerative braking mode in Fig. 18(c), compared to Fig. 18(d). Fig. 19 is the standstill charging, in this mode, PV charges the battery by driving topology and SRM phase winding; the three phases are in parallel working mode. Fig. 19 illustrates the battery charging waveforms in stand still condition. In Fig. 19(a), the battery is charged by PV panel; $P_{z}$ is the rotor position sensor signal that keeps at zero proof the proposed standstill charging doesn't influence the electrical vehicle. In Fig. 19(b), the battery is charged by AC source; by the proposed hysteresis control, the grid current (THD) is 4.716\%; and the corresponding THD analysis waveform is presented in Fig.19 (c), which meets the requirement of the international standards IEC61727 and IEEE1547.

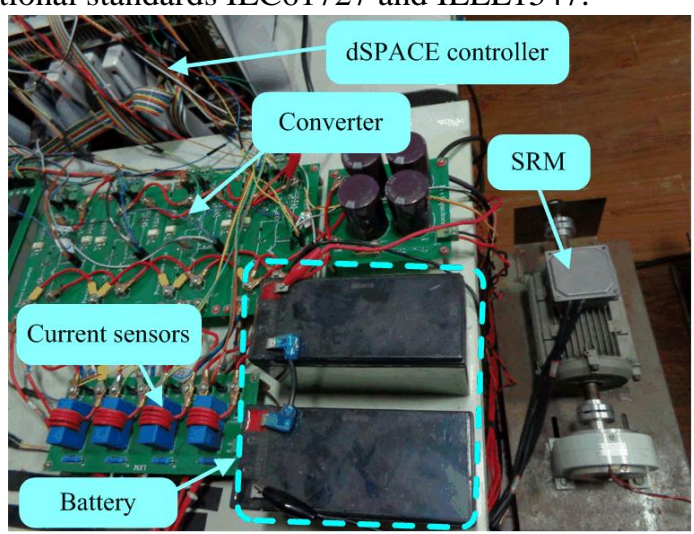

Fig. 16. Experimental setup of the proposed SRM drive system.

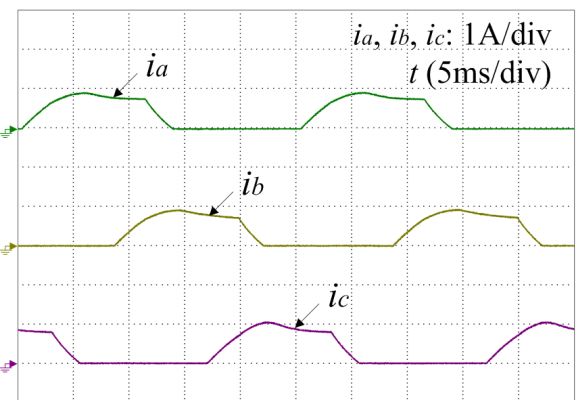

(a) $300 \mathrm{rpm}$ at modes 2, 3 and 4 .

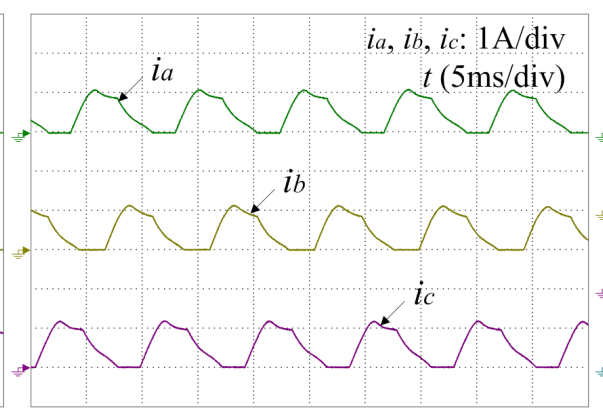

(b) $800 \mathrm{rpm}$ at modes 2, 3 and 4 .

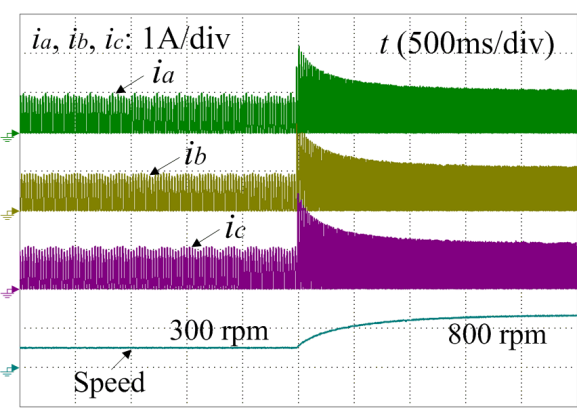

(c) Acceleration at modes 2, 3 and 4.

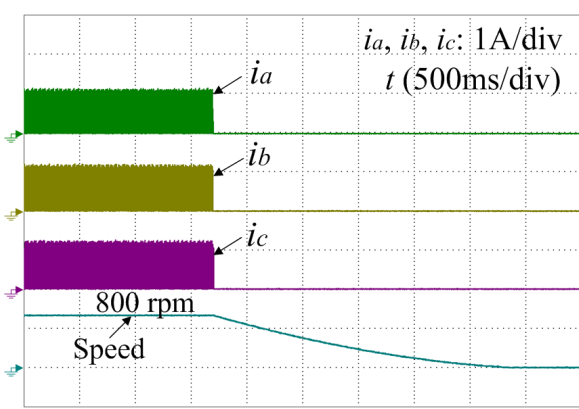

(d) Inertial braking at modes 2, 3 and 4 .

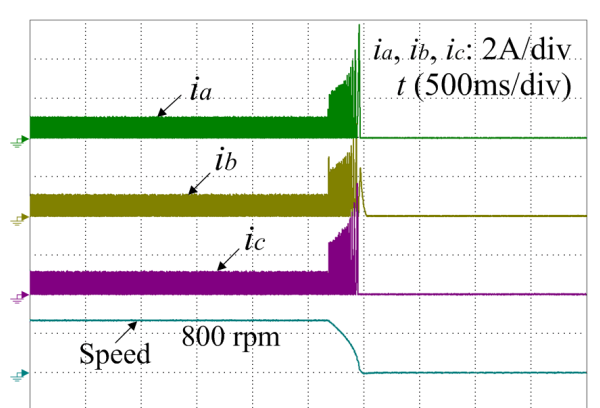

(e) Regenerative braking at modes 2, 3 and 4 .

Fig. 17. Motoring and braking modes when $\mathrm{J} 1$ is on (modes 2, 3 and 4).

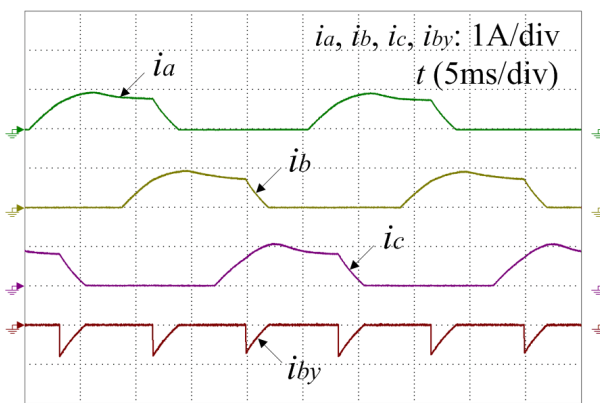

(a) $300 \mathrm{rpm}$ a

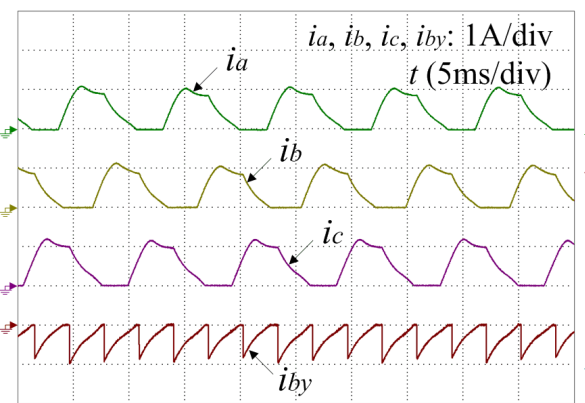

(b) $800 \mathrm{rpm}$

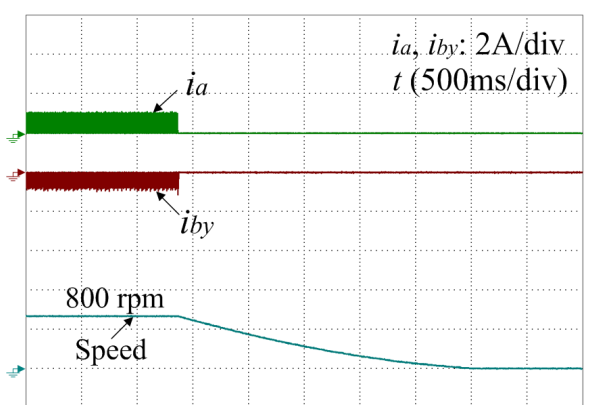

(c) Inertial braking at-mode 1 


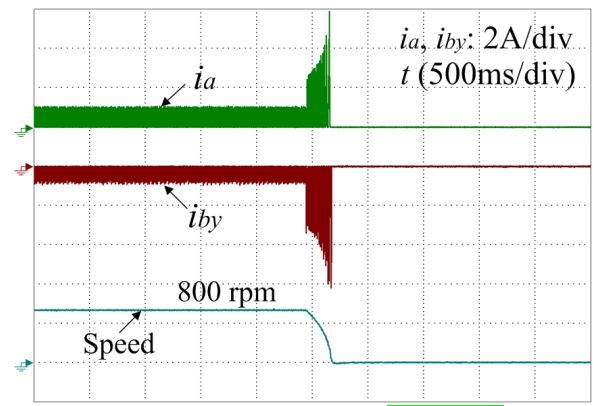

Fig. 18. Motoring and braking modes when J1 is off (mode1).

(d) Regenerative braking

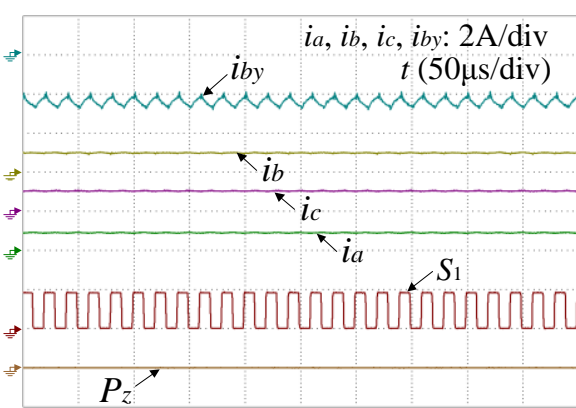

(a) Standstill charging at-mode 5 .

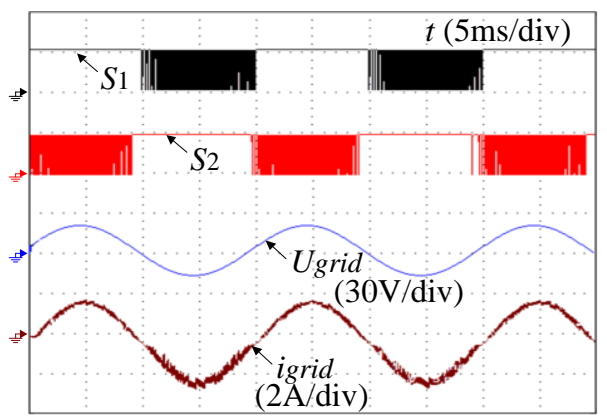

(b) AC source charging at-mode 5 .

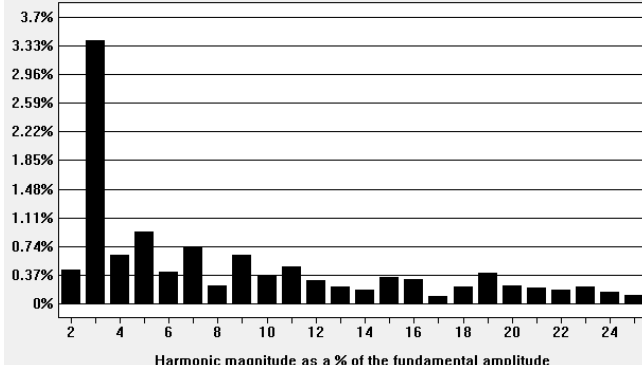

(c) THD analysis at-mede 5 .

Fig. 19 Charging experiment waveform in stand still condition (mode 5).

\section{CONCLUSION}

In order to tackle the range anxiety of using EVs and decrease the system cost, a combination of the PV panel and SRM is proposed as the EV driving system.

The main contributions of this paper are:

(i) A tri-port converter is used to coordinate the PV panel, battery and SRM.

(ii) Six working modes are developed to achieve flexible energy flow for driving control, driving/charging hybrid control and charging control.

(iii) A novel grid-charging topology is formed without a need for external power electronics devices.

(iv) A PV-fed battery charging control scheme is developed to improve the solar energy utilization.

Since PV-fed EVs are a greener and more sustainable technology than conventional ICE vehicles, this work will provide a feasible solution to reducing the total costs and $\mathrm{CO}_{2}$ emissions of electrified vehicles. Furthermore, the proposed technology may also be applied to similar applications such as fuel cell powered EVs fuel cells have a much higher power density and are thus better suited for EV applications. The proposed topology gives one of the low cost solutions for fuel eell powered EV.

\section{REFERENCES}

[1] A. Emadi, L. Young-Joo, K. Rajashekara, "Power electronics and motor drives in electric, hybrid electric, and plug-in hybrid electric vehicles," IEEE Trans. Ind. Electron., vol. 55, no. 6, pp. 2237-2245, Jun. 2008.

[2] B. 1. K. Bose, "Global energy scenario and impact of power electronics in 21 st century," IEEE Trans. Ind. Electron., vol. 60, no. 7, pp. 2638-2651, Jul. 2013.

[3] J. de Santiago, H. Bernhoff, B. Ekergård, S. Eriksson, S. Ferhatovic, R. Waters, and M. Leijon,"Electrical motor drivelines in commercial allelectric vehicles: a review," IEEE Trans. Veh. Technol., vol. 61, no. 2, pp. 475-484, Feb. 2012.
[4] Z. Amjadi, S. S. Williamson, "Power-electronics-based solutions for plugin hybrid electric vehicle energy storage and management systems," IEEE Trans. Ind. Electron., vol. 57, no. 2, pp. 608-616, Feb. 2010.

[5] A. Kuperman, U. Levy, J. Goren, A. Zafransky, and A. Savernin, "Battery charger for electric vehicle traction battery switch station," IEEE Trans. Ind. Electron., vol. 60, no. 12, pp. 5391-5399, Dec. 2013.

[6] S. G. Li, S. M. Sharkh, F. C. Walsh, and C. N. Zhang, "Energy and battery management of a plug-in series hybrid electric vehicle using fuzzy logic," IEEE Trans. Veh. Technol., vol. 60, no. 8, pp. 3571-3585, Oct. 2011.

[7] C. H. Kim, M. Y. Kim, and G. W. Moon, "A modularized charge equalizer using a battery monitoring IC for series-connected Li-Ion battery Strings in electric vehicles," IEEE Trans. Power Electron., vol. 28, no. 8, pp. 3779-3787, May 2013

[8] Z. Ping, Z. Jing, L.Ranran, T. Chengde, W. Qian, "Magnetic characteristics investigation of an axial-axial flux compound-structure PMSM used for HEVs," IEEE Trans. Magnetics, vol. 46, no. 6, pp. 21912194, Jun. 2010.

[9] A. Kolli, O. Béthoux, A. De Bernardinis, E. Labouré, and G. Coquery, "Space-vector PWM control synthesis for an H-bridge drive in electric vehicles," IEEE Trans. Veh. Technol., vol.62, no.6, pp. 2441-2452, Jul. 2013.

[10] S. M. Yang, and J. Y. Chen, "Controlled dynamic braking for switched reluctance motor drives with a rectifier front end," IEEE Trans. Ind. Electron., vol. 60, no. 11, pp. 4913- 4919, Nov. 2013.

[11] B. Bilgin, A. Emadi, M. Krishnamurthy, "Comprehensive evaluation of the dynamic performance of a 6/10 SRM for traction application in PHEVs," IEEE Trans. Ind. Electron., vol. 60, no. 7, pp. 2564-2575, July. 2013.

[12] M. Takeno, A.Chiba, N. Hoshi, S. Ogasawara, M. Takemoto, M. A. Rahman, "Test results and torque improvement of the $50-\mathrm{kW}$ switched reluctance motor designed for hybrid electric vehicles," IEEE Trans. Ind. Appl., vol. 48, no. 4, pp. 1327-1334, Jul/Aug. 2012.

[13] A. Chiba, M. Takeno, N. Hoshi, M. Takemoto, S.Ogasawara, M. A. Rahman, "Consideration of number of series turns in switched-reluctance traction motor competitive to HEV IPMSM," IEEE Trans. Ind. Appl., vol. 48, no. 6, pp. 2333-2340, Nov/Dec. 2012.

[14] I. Boldea, L. N. Tutelea, L. Parsa, and D. Dorrell, "Automotive electric propulsion systems with reduced or no permanent magnets: an overview," IEEE Trans. Ind. Electron., vol. 60, no. 9, pp. 5696- 5710, Oct. 2014.

[15] H. C. Chang, C. M. Liaw, "An integrated driving/charging switched reluctance motor drive using three-phase power module," IEEE Trans. Ind. Electron., vol. 58, no. 5, pp. 1763-1775, May 2011.

[16] X. D. Xue, K. W. E. Cheng, T. W. Ng, N. C. Cheung, "Multi-objective optimization design of in-wheel switched reluctance motors in electric vehicles," IEEE Trans. Ind. Electron., vol. 57, no. 9, pp. 2980-2987, Sep. 2010. 
[17] Y. J. Lee, A. Khaligh, A. Emadi, "Advanced integrated bidirectional AC/DC and DC/DC converter for plug-in hybrid electric vehicles," IEEE Trans. Veh. Technol., vol. 58, no. 8, pp. 3970-3980, Oct. 2009.

[18] M. Yilmaz, P.T. Krein, "Review of battery charger topologies, charging power levels, and infrastructure for plug-in electric and hybrid vehicles," IEEE Trans. Power Electron., vol. 28, no. 5, pp. 2151-2169, May 2013.

[19] A. Khaligh, S. Dusmez, "Comprehensive topological analysis of conductive and inductive charging solutions for plug-in electric vehicles," IEEE Trans. Veh. Technol., vol. 61, no. 8, pp. 3475-3489, Oct. 2012.

[20] S. Haghbin, S. Lundmark, M. Alakula, and O. Carlson, "Grid-connected integrated battery chargers in vehicle applications: review and new solution," IEEE Trans. Ind. Electron., vol. 60, no. 2, pp. 459-473, Feb. 2013.

[21] S. Haghbin, S. Lundmark, M. Alakula, and O. Carlson, "An isolated high power integrated charger in electrified-vehicle applications," IEEE Trans. Veh. Technol., vol. 60, no. 9, pp. 4115-4126, Nov. 2011.

[22] S. Haghbin, K. Khan, S. Zhao, M. Alakula, S. Lundmark, O. Carlson, "An integrated $20-\mathrm{kW}$ motor drive and isolated battery charger for plug-in vehicles," IEEE Trans. Power Electron., vol. 28, no. 8, pp. 4013-4029, Aug. 2013.

[23] H. C. Chang, C. M. Liaw, "Development of a compact switchedreluctance motor drive for EV propulsion with voltage-boosting and PFC charging capabilities," IEEE Trans. Veh. Technol., vol. 58, no. 7, pp. 3198-3215, Sept. 2009.

[24] H. C. Chang; C. M. Liaw, "An integrated driving/charging switched reluctance motor drive using three-phase power module," IEEE Trans. Ind. Electron., vol. 58, no. 5, pp. 1763-1775, May 2011.

[25] Y. Hu, X. Song, W. Cao, B. Ji, "New SR drive with integrated charging capacity for plug-in hybrid electric vehicles (PHEVs)," IEEE Trans. Ind. Electron., vol. 61, no. 10, pp. 5722-5731. Oct. 2014. 